\title{
Arte público en internet: precedentes y novedades del catálogo on line en la web municipal de Zaragoza
}

\author{
JESÚS PEDRO LORENTE* \\ Universidad de Zaragoza \\ e-mail: jpl@unizar.es
}

\section{Resumen}

Este artículo analiza el catálogo on line de arte público incluido en la web del Ayuntamiento de Zaragoza, sus precedentes aragoneses y equivalentes en otros contextos.

\begin{abstract}
This paper analyzes the on line catalogue of public art hosted by the web of Zaragoza local council, together with previous Aragonese examples and its equivalents in other contexts.
\end{abstract}

\footnotetext{
* Investigador principal del proyecto "Arte público para todos: propuestas de estudio y musealización virtual" financiado por el Ministerio de Ciencia e Innovación (código HAR200913989-C02-02) desde diciembre 2009 a diciembre 2012.
} 
El arte público tiene un creciente protagonismo en internet, con lo cual su carácter "público" se está viendo reforzado, pues no sólo lo encuentran los ciudadanos -incluso los que no son aficionados al arte, ni frecuenten galerías o museos- cuando pasean por las calles, plazas, parques y espacios naturales, sino que además pueden hallar presentaciones sobre arte público al "navegar" por páginas web, en las que quizá han recalado llevados por otros intereses. Por ejemplo cuando algunos amigos nos envían a través de las redes sociales imágenes de los monumentos que han visitado, o cuando colgamos en Flickr u otras aplicaciones de photo-sharing fotografías de lo más destacado de nuestra ciudad o de otras. O cuando consultamos y curioseamos datos en internet para preparar o soñar un posible viaje a nuestras ciudades favoritas: un caso muy conocido y digno de destacar, pues incluye gran variedad de hitos del patrimonio artístico visitables en los cinco continentes, es el de "Insecula: Guide intégral du voyageur"1, por no citar las páginas web de agencias de viaje $\mathrm{u}$ oficinas de turismo especializadas en destinos concretos. Pero más remarcable aún es el caso de los portales de instituciones oficiales, a los que llega el ciudadano para realizar una gestión, consultar una información $\mathrm{u}$ otros menesteres, y se topa por casualidad con un atractivo catálogo de arte público, como es el caso del que se ofrece en el del Ayuntamiento de Barcelona². No es un servicio inusitado, pues ya es rara la

\footnotetext{
${ }_{1}^{1}$ Este portal tiene foros sobre arte y museos, urbanismo y arquitectura, viajes y ciudades, exposiciones, y otros temas, y es accesible en inglés http:/faceagain.worldvisitguide.com/ o en francés http://www.insecula.com (web consultada el 27/02/2012).

2 Según reza la introducción explicativa que allí se ofrece, esta web "presenta el Catálogo razonado de las esculturas y otras obras artísticas situadas en el espacio público de la ciudad de Barcelona o bien visibles desde él" (...) "La mayoría de ellas son ahora de propiedad pública, otras son de propiedad privada, y otras forman parte de los antiguos jardines privados que se han convertido en espacios públicos, pero todas ellas son ahora elementos de representación y de identidad. El Catálogo ha omitido los elementos seriados de mobiliario urbano. Los 1351 conjuntos que se presentan de los que se pueden individualizar 1676 obras, permiten seguir no tan solo la evolución de la escultura en Cataluña a lo largo de los últimos ochocientos años, sino también la de la historia catalana. El Catálogo incluye también los monumentos desaparecidos, las intervenciones artísticas vinculadas a las infraestructuras de transporte como el Metro, las situadas en los recintos de los cementerios, las placas conmemorativas, y los elementos seriados de mobiliario urbano. Por razones metodológicas, que no conceptuales, en esta versión no se han incluido los monumentos proyectados pero no construidos de los que se tiene constancia documental, ni los programas escultóricos de las fachadas de los edificios públicos. A partir de estas premisas el Catálogo pretende ser
} 
ciudad de cualquier país desarrollado que no tiene una página web con, entre otras cosas, informaciones sobre sus atractivos patrimoniales; pero llama la atención que, aunque sólo sea por mor del orden alfabético, "Art Públic" este rótulo en catalán permanece invariable, incluso en las versiones del portal en español o en inglés- figure entre las primeras opciones del menú que aparece a la izquierda de la página de inicio, de manera que es una de las primeras cosas que encuentran los ojos del visitante. Se trata además, como ya queda dicho, de un reclamo muy atractivo, por su diseño y la variedad de recursos o búsquedas ofrecidas. $Y$ también tienen sus contenidos una calidad científica muy superior a lo que suele ser habitual en los portales de otros municipios (véase LORENTE, 2007), pues no se planteó como un texto de divulgación encomendado a plumas bisoñas, sino como una labor de especialistas $^{3}$ realizada en el marco de un proyecto de investigación titulado "Arte público en el desarrollo urbano: sistema de consulta interactivo por internet", dirigido por el prof. Antoni Remesar y financiado por el Ministerio de Educación desde diciembre de 2002 a noviembre de 2005. Este catálogo se insertó en la web municipal en 2004, el año en que Barcelona organizó el Forum Internacional de las Culturas; pero luego se ha continuado la labor con otro proyecto titulado elocuentemente "Hacia el museo virtual europeo de arte público. Sistemas de información y gestión on-line del arte público", vigente desde diciembre de 2005 a noviembre de 2006. ¿Por qué este nuevo título de "museo virtual"? Porque los miembros del equipo estábamos convencidos de que era algo más que un catálogo, pues además de estudiar y catalogar realizábamos otras de las funciones principales de un museo, como exponer, difundir y explicar, e incluso estábamos colaborando en la conservación de las piezas, pues gracias a la colaboración ciudadana de los usuarios de este servicio se estaba señalando al Ayuntamiento qué piezas habían sufrido algún desperfecto o ataque vandálico, permitiendo una rápida intervención de los encargados de su limpieza o restauración.

exhaustivo sin considerar criterios de valoración". Ajuntament de Barcelona, Art Públic, http://www.bcn.es o http://www.bcn.cat (web consultada el 27/02/2012).

${ }^{3}$ Figuran en los créditos de la citada presentación del mismo en internet los tres editores, por una parte Ignasi de Lecea y Carme Grandas en el Sector de Urbanismo del Ayuntamiento de Barcelona, y por otra Antoni Remesar, del Departamento de Escultura de la Universidad de Barcelona, más una larga lista de nombres de los demás autores. Ajuntament de Barcelona, Art Públic, http:/www.bcn.es o http://www.bcn.cat (web consultada el 27/02/2012). 
Hay que reconocer que la denominación "museo virtual", que está cada vez más en boga, se está empleando con significados muy diversos y sólo en los últimos años se ha ido clarificando un poco su uso más apropiado. Expertos en el tema, como Sergio Talens Oliang, José Hernández Orallo, Arturo Colorado Castellary, o Antonio Cerveira Pinto, proponen (según se recoge en BELLIDO, 2001: 237-259) llamar "museo digital" al diseño informático de un supuesto museo, en el que se emula la exposición de obras de arte digital, mientras que cuando las obras evocadas sí corresponden a creaciones artísticas materiales e incluso su exposición conjunta reproduce la existente en un museo o colección real, prefieren hablar de "museo virtual". No es necesario que se reproduzcan el recorrido por las galerías de exposición y los demás espacios del museo real, como por ejemplo hace con espectaculares resultados la página web del Rijksmuseum de Ámsterdam, pues el mayor interés de un museo virtual no es presumir de efectos tecnológicos, sino el hecho de presentar en un portal una colección que a veces corresponde a la de un museo real, pero a menudo es una reunión virtual de piezas desperdigadas por diferentes territorios (MCTAVISH, 2006) ${ }^{4}$. En este sentido, bien podría decirse que la reunión de fotografías de obras artísticas de cualquier lugar del mundo que coleccionó Malraux en su despacho ya era un museo virtual, y de hecho su "museo imaginario" es uno de los ejemplos favoritos aducidos como antecedente por quienes han abordado este debate terminológico no desde las nuevas tecnologías sino desde la filosofía y la estética (como DELOCHE, 2002 y MARCHÁN FIZ, 2005); pero aún se podrían rastrear precedentes históricos, como las boîtes-en-valise de Duchamp, o el Liber Studiorum de Turner, un álbum de grabados donde el pintor inglés guardaba reproducciones de sus cuadros, de los que tanto le costaba separarse.

\footnotetext{
${ }^{4}$ Para más información sobre este tema véase el monográfico sobre museos virtuales de boletín ICOM News, vol. 57 (2004), n 3, consultable en internet: http://com.museum/news.html (web consultada el 04/06/2008) y la bibliografía sobre museos virtuales colgada en el sitio web del ICOM titulado "Bibliography: Virtual Museums / Bibliographie: Musées virtuels", en http://icom.museum/biblio_virtual.html (web consultada el 27/02/2012). A los libros allí citados, cabe añadir algunos posteriores de expertos españoles (e.g.: CARRILLO, 2004; CARRERAS y Munilla, 2005). También hay frecuentes artículos sobre museos e Internet en la revista electrónica Telos: Cuadernos de Comunicación e Innovación, publicada trimestralmente por Fundación Telefónica y consultable en www.telos.es
} 
Hechas estas consideraciones, ya quedará claro que un sitio donde pueden encontrarse imágenes y datos de las obras de arte público de una determinada ciudad también será un museo virtual, y más si se proponen allí itinerarios, visitas por distrito urbano, y consultas interactivas por autor, tema, periodo histórico, etc. Todo esto, o buena parte de lo dicho, se hallará en algunas páginas web emanadas de proyectos de investigación en curso, pues precisamente una de las áreas declaradas prioritarias por nuestro Ministerio de Educación es la difusión y estudio del patrimonio mediante las nuevas tecnologías 5 . En el caso del equipo liderado por el prof. Antoni Remesar, desde 2006 hemos constituido una red de proyectos coordinados desde diferentes Universidades y mientras él sigue siendo el investigador principal de un proyecto financiado por el Ministerio hasta diciembre de 2009 titulado "Arte público y diseño urbano para todos", gracias al cual se continua ampliando el "museo virtual" de arte público barcelonés que sigue desarrollando junto con Carme Grandas, otro equipo constituido por investigadores de la Universidad de Zaragoza, el Ayuntamiento de esta ciudad, y otras instituciones aragonesas, estamos encuadrados en el proyecto "Arte público para todos: su musealización virtual y difusión social".

Sin duda, el ejemplo de lo realizado en Barcelona ha sido un modelo y estímulo para los que anhelábamos hacer algo similar en Aragón, donde hasta

\footnotetext{
${ }^{5}$ Basta ojear las listas de los proyectos concedidos por el Ministerio en los últimos años para comprobar el incremento de este tipo de investigaciones, entre las que no resisto la tentación de señalar, por ejemplo, el proyecto titulado "Arte y ecología en la sociedad digital", dirigido por la profesora Lourdes Cirlot en la Universidad de Barcelona, donde están configurando un corpus de artistas y obras, cursos, seminarios, etc (aparte de organizar unas Jornadas sobre Arte, arquitectura y sociedad digital, de las que ha resultado un libro de autoría colectiva: Cirlot, BuXó, CASANOVAS, EstéveZ, 2007). Hay también proyectos de investigación que incluso tienen por objetivo crear un "museo virtual", como el titulado "Ecomuseo itinerante: Diseño y desarrollo de una estructura didáctica para la gestión cultural y turística del patrimonio. Un modelo sostenible para las Islas Canarias, proyecto dirigido por la profesora $\mathrm{M}^{\mathrm{o}}$ Victoria Batista Pérez, de la Universidad de La Laguna que ha puesto en marcha la web "Ecomuseo Itinerante", http://www.ecomuseoitinerante.com, que pretende didácticamente "la puesta en marcha de itinerarios temáticos, con la visita y desarrollo de actividades en lugares donde confluyen elementos patrimoniales significativos relacionados con un determinado tema" (web consultada el 04/06/2008), o el proyecto titulado "Creación de un museo virtual de etnografía escolar de la España Contemporánea" cuyo responsable es el profesor de la Universidad Complutense Julio Ruiz Berrio.
} 
ahora ha habido en relación con el tema de este artículo modestas pero muy loables iniciativas particulares y alguna de tipo institucional (LORENTE, 2008b). Entre las primeras interesa aquí destacar, por su veteranía y su relación con el arte público, la que abrió en 1999 un grupo de guasones fans de la cultura pop bajo el lema de "Zaragoza de luxe", cuya página de inicio está presidida por una imagen procedente de un libro turístico editado en 1973 en donde aparece una Virgen del Pilar que remeda a los cliks de Playmobil y con una corona en forma de disco de vinilo (fig. 1). El sitio está estructurado en secciones, algunas de ellas divididas en plantas y salas, como si se tratara de un museo, donde se rastrean vestigios de la cultura pop por la ciudad de Zaragoza — hay una sección internacional en construcción, donde se recogerán ejemplos de otras ciudades del resto de España y del mundotanto en el diseño de tiendas y pasajes comerciales, rótulos de bares o discotecas, arquitecturas singulares, $u$ otros elementos de la ciudad, incluidos algunos ejemplos de arte público, como el monumento a Paco Martínez Soria en el Parque Primo de Rivera, que merece un comentario muy sarcástico ${ }^{6}$. De algunas de estas imágenes el visitante puede hacer ampliaciones y enviar postales electrónicas, pero la interactividad viene aquí marcada sobre todo por la sección "Foro de discusión" y por la invitación que se hace en todas las secciones para que se les envíen fotos y comentarios de ejemplos adicionales, cuyos remitentes figurarán en la lista de colaboradores. Por supuesto, se ofrecen también enlaces con otras páginas web.

Las demás iniciativas privadas que han ido surgiendo en Aragón cubren un amplio espectro de intereses, desde los blogs y páginas web personales de algún artista o colectivo artístico, a ejemplos de revistas que interesa reseñar aquí por su especialización en temas de museos y exposiciones. Entre estos últimos, entre otras revistas digitales con importante dedicación al arte público, como la revista de la Asociación Aragonesa de Críticos de Arte

\footnotetext{
${ }^{6}$ Es el segundo ejemplo recogido en la sección "Otros", y junto la fotografía del monumento viene acompañada del siguiente texto: "HOMENAJE (¿) A PACO MARTINEZ SORIA/Parque Grande/Debía ser un enemigo del actor quien perpetró semejante cosa. La cabeza de Paco Martínez Soria (a quien no se parece en absoluto) emergiendo de lo que parece ser una campana extractora de humos, rodeado de una especie de instalación parecida a un transportador de materia cósmica. Aterrador."

Zaragoza de Luxe, http://www.zaragozadeluxe.com (consultado el 27/02/2012).
} 
(http://www.aacadigital.com), sin duda el caso más sobresaliente es la publicación digital "Cuadernos de Cazarabet", que con el subtítulo de "Revista de museología e iniciativas de la sociedad civil aragonesa en torno al patrimonio cultural" publica cada mes Javier Díaz Soro, desde Mas de las Matas, un pueblecito del Bajo Aragón turolense?.

Pero, tras tributar el merecido reconocimiento a estas estimables iniciativas de nuestra sociedad civil, es preciso reconocer que ninguna está especializada en el tema objeto de este artículo. Hasta ahora, el arte público aragonés sólo era divulgado en internet a través de una excelente iniciativa pedagógica: el portal sobre "Escultura urbana en Zaragoza" ofrecido en la página web del colegio público Cesáreo Alierta de Zaragoza por su profesor secretario, Armando González Gil, cuando el centro organizó en 2004 unas jornadas culturales con el objetivo de que el alumnado conociera la escultura pública de su ciudad y tomara conciencia de lo importante que era el respetarla y cuidarla al ser patrimonio de todos los ciudadanos. El nivel de información de este catálogo es digno de elogio, teniendo en cuenta que una sola persona es responsable de todas las informaciones que allí se ofrecen, y de todo el diseño del portal, que ahora ha ampliado su campo de actuación a la escultura pública en Aragón, y permite la consulta por comarcas e incluso por opciones temáticas ${ }^{8}$ (fig. 2). Por su vocación de divulgación pedagógica, se trata de un portal muy popular, pues es recomendado en otros colegios, y hasta ha servido como instrumento de consulta en un programa de Radio Zaragoza donde se preguntaba a los oyentes sobre la identificación y datos curiosos relativos a los monumentos zaragozanos. También ha colaborado a su importante número de visitantes —más de 1.500 anuales - el hecho de que

\footnotetext{
7 (http://www.cazarabet.com/cuadernos/index.htm). Es una prueba más de que en la actual aldea global gracias a las nuevas tecnologías ya no existe la periferia, al menos en términos de información, que es en este caso el punto fuerte - se trata sobre todo de un boletín informativo, pues no suele haber artículos de crítica firmados por comentaristas externos-.

${ }^{8}$ Por eso, el año 2011 cambió el título original de este portal, que ahora se llama "Aragón Escultura Urbana", y se ha ido enriqueciendo con nuevas informaciones y fotos no sólo relativas a esculturas en espacios urbanos sino también a esculturas públicas en plena naturaleza. Eso sí, aunque las 320 obras catalogadas en la capital aragonesa estén ya en minoría, siguen teniendo un tratamiento especial con listado alfabético por títulos, cfr. http://www.esculturaurbanaaragon.com.es/(web consultada el 27/02/2012).
} 
sea recomendado en otros portales abiertos en internet sobre temas parecidos, como el ya citado de Barcelona, o el de la revista digital Escultura Urbana 9 .

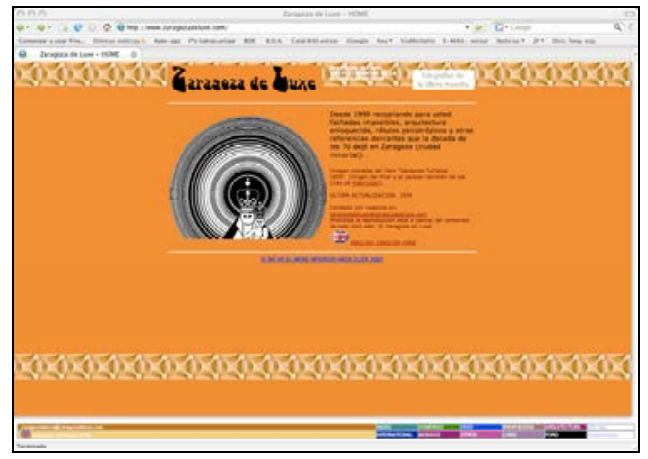

Fig. 1: Página de inicio del portal "Zaragoza de Luxe" (http://www.zaragozadeluxe.com)

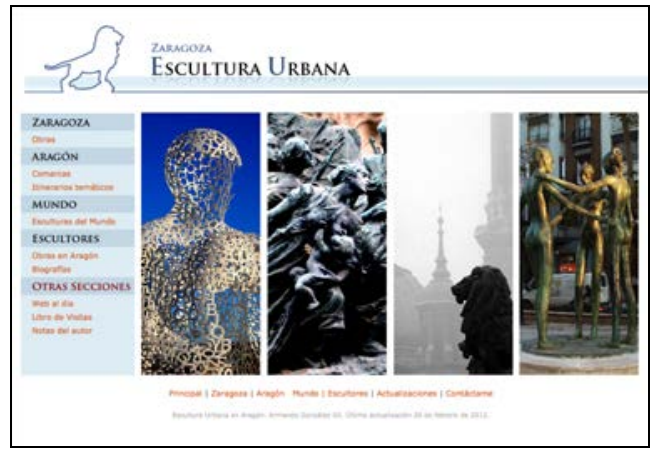

Fig 2: Página de inicio de la guía didáctica "Escultura urbana en Aragón" (http://www.esculturaurbanaaragon.com.es)

Párrafo aparte merecen, pues entramos ya en el ámbito institucional al que preferentemente se refiere este artículo, los catálogos e informaciones relacionados con el tema que ofrecen portales dependientes de las administraciones públicas. El Gobierno de Aragón, con el apoyo de Ibercaja, ha creado en 2007 uno dedicado a los monumentos y bienes inmuebles incluidos en el Catálogo del Patrimonio Cultural de Aragón, para cumplir con lo que se indica en la Ley de Patrimonio Cultural Aragonés, según la cual su inclusión en dicha categoría no sólo obliga a su protección, sino también a su estudio y difusión (http: www.patrimonioculturaldearagon.com). Sólo constan en él yacimientos y edificios o conjuntos arquitectónicos; algunos de ellos en Zaragoza, como la Puerta del Carmen (fig. 3); pero puede ser complementado por el portal de colecciones en red de los museos españoles, donde hay incluidas algunas obras aragonesas expuestas al aire libre (fig. 4).

(http://servicios3.aragon.es/reddigitalA/pages/SimpleSearch?index=true)

\footnotetext{
${ }^{9}$ La revista mensual Escultura urbana, se presenta a sí misma como "la primera revista digital dedicada a la escultura pública en España" (http://esculturaurbana.com; consulta realizada el 27/02/2012); pero es algo más que una revista de novedades e información general sobre estos temas, pues en su web también se ofrece un catálogo de escultura pública al que se puede acceder por índice alfabético de autores o por localidades ordenadas por provincias.
} 
Arte público en Internet: precedentes y novedades del catálogo on line...

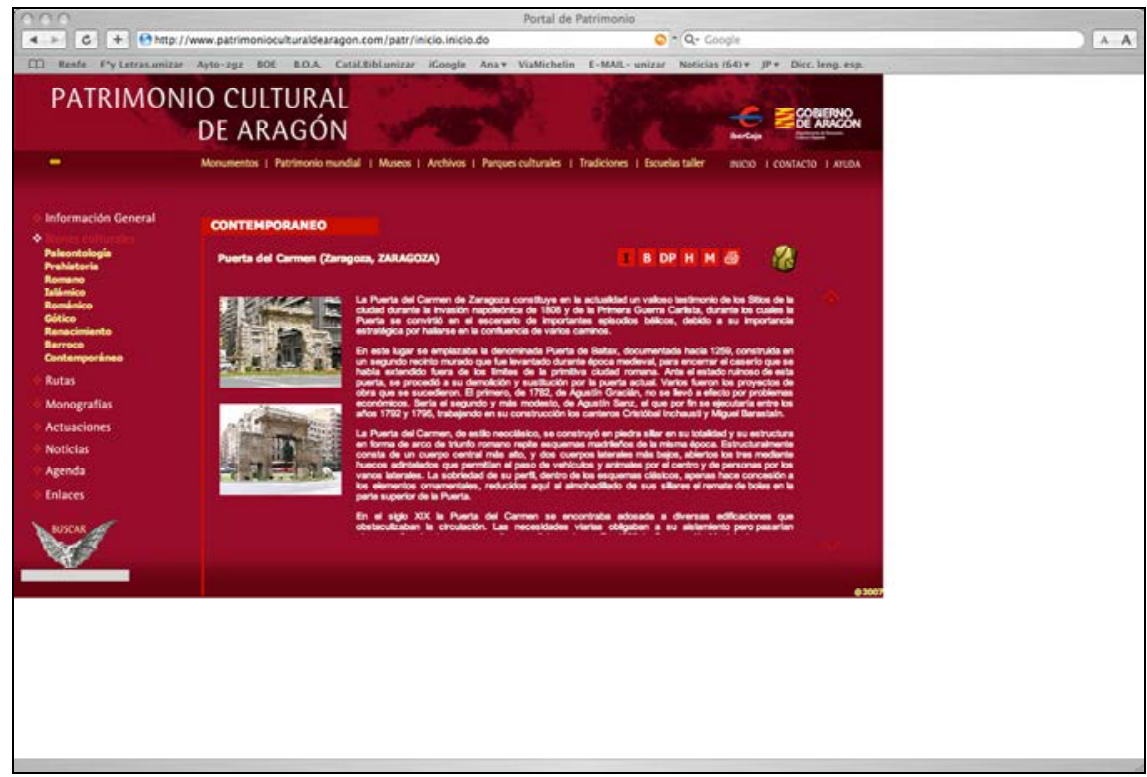

Fig. 3: Ficha catalográfica de la Puerta del Carmen en el portal "Patrimonio Cultural de Aragón" (http://www.patrimonioculturaldearagon.com)

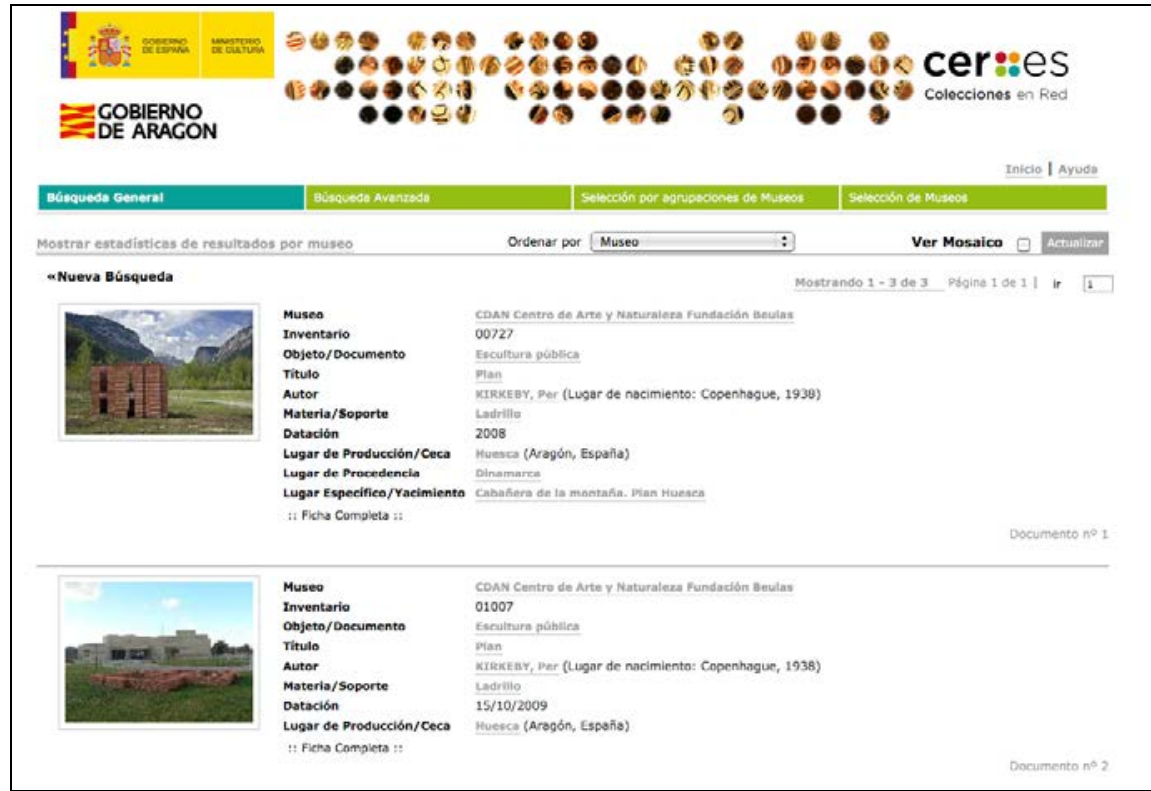

Fig. 4 Fichas catalográficas de dos esculturas al aire libre de Per Kirdeby en el catálogo on line Cer.es (http://servicios3.aragon.es/reddigitalA/pages/Main) 
Por su parte, en la web del Ayuntamiento de Zaragoza se ofrece un catálogo razonado de 1.369 edificios considerados de interés histórico artístico, que fue elaborado en 2005 por el Departamento de Historia del Arte de la Universidad de Zaragoza y la Gerencia de Urbanismo del Ayuntamiento de Zaragoza $^{10}$. Actualmente es accesible desde diferentes rincones de la web municipal, pues se han realizado enlaces en otros apartados —incluido el catálogo on line de arte público-; pero inicialmente estuvo colgado dentro del menú de "Urbanismo", que sigue siendo su sitio principal: una vez allí hay que hacer clic en "Planeamiento" en cuya persianilla desplegable se debe escoger la entrada "Edificios de interés histórico-artístico". Lo ideal para una mejor accesibilidad sería colgarlo en un lugar más visible de la web del Ayuntamiento de Zaragoza, para que cualquier investigador, periodista o curioso que entre por allí lo encuentre en seguida. Por otro lado, desde el punto de vista de una mejor usabilidad, sería deseable que se procesase cada uno de los campos de información del catálogo para que si, por ejemplo, alguien escribe el nombre de un arquitecto en el buscador del portal municipal, aparecieran las fichas de sus edificios catalogados. En todo caso, es un trabajo muy a tener en cuenta de cara al "museo virtual" de arte público, no sólo como antecedente de cuyos aciertos y errores tenemos que aprender, sino también porque esos PDFs incluyen algún monumento que también aparece en las fichas del catálogo on line de arte público, por ejemplo la ya

10 Este catálogo de edificios protegidos era un requisito establecido en Plan General de Ordenación Urbana de 2002, y se responsabilizó del mismo el Servicio de Patrimonio Cultural Urbanístico de la Dirección de Servicios de Planificación y Diseño Urbano, aunando las aportaciones presentadas por ciudadanos particulares, por la Comisión Municipal de Patrimonio Histórico Artístico y otras áreas municipales, así como la colaboración específica del Departamento de Historia del Arte de la Universidad de Zaragoza, fruto del convenio suscrito por la Gerencia de Urbanismo, para llevar a cabo un trabajo riguroso en el que participaron grupos de becarios de investigación y estudiantes de Tercer Ciclo, bajo la supervisión de un comité de expertos. Este documento detalla cuáles son los elementos por los que se cataloga un edificio, cuáles hay que conservar en una posible intervención arquitectó-nica, y qué tipo de intervención habría que hacer. De los 1369 edificios protegidos en total, el Casco Histórico concentra 1017 edificios catalogados, 363 se ubican en el resto de la ciudad y 93 en barrios rurales. Quien consulte la web municipal puede bajarse un PDF de cada ficha catalográfica, donde se ofrece una descripción histórica de cada uno de los edificios, fotografías de su estado actual, localización en el plano con su ubicación, descripción del edificio y por qué se considera que debe estar en el catálogo, así como su grado de catalogación. 
citada Puerta del Carmen, el Altar Patrio, o el Monumento a Alfonso I el Batallador en lo alto del Cabezo de Buenavista (fig. 5).

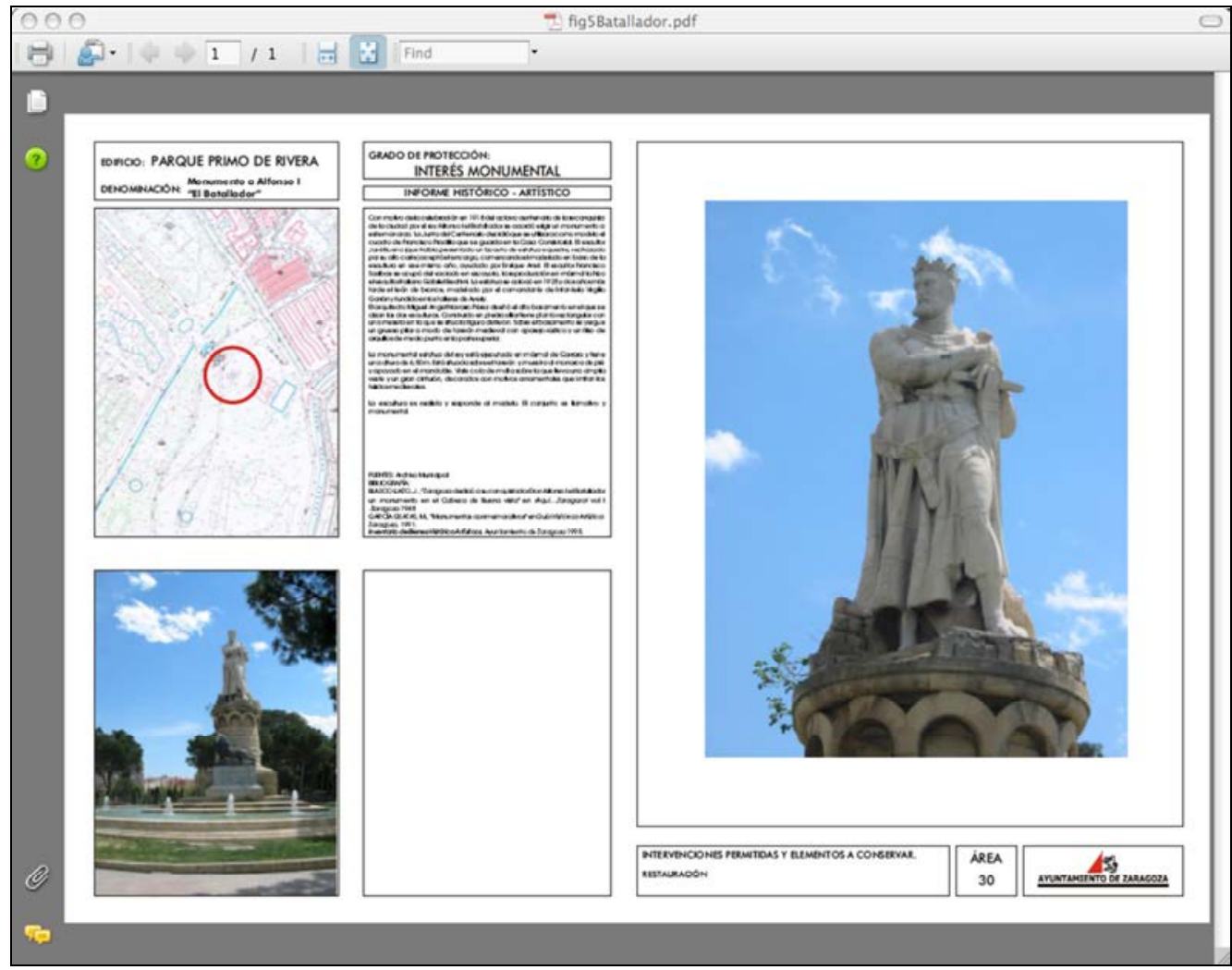

Fig. 5: Ficha del Monumento a Alfonso I el Batallador en el catálogo razonado de edificios considerados de interés histórico artístico en la web municipal. (http://www.zaragoza.es/ciudad/urbanismo/planeamiento/buscar_Catalogo)

Por otra parte, en el propio apartado "La Ciudad" de la página web del consistorio zaragozano, como en tantas otras de distintas corporaciones locales en nuestro país, uno encuentra en seguida imágenes de sus principales atractivos turísticos y ciudadanos. En esto quizá el caso de Zaragoza sea uno de los más destacados por la profusión de información visual, pues a partir de la carpeta "Vistas de la Ciudad" se puede enlazar con infinidad de imágenes zaragozanas, si bien uno echa de menos alguna estructura o 
jerarquización clara de dicha información ${ }^{11}$. Por su relación con el arte público, interesa aquí destacar el rótulo "Envía una Postal", donde uno encuentra, listas para mandar por correo electrónico a algún amigo, nada menos que cien postales distribuidas en nueve secciones por épocas históricas o u otras categorías, siendo la más directamente relacionada con el tema de este artículo la titulada "Otros Monumentos Contemporáneos", donde aparecen ocho famosas esculturas monumentales. Lástima que los comentarios que acompañan a todas estas postales — que reproducen unos folletos editados por el Patronato Municipal de Turismo - sean casi siempre muy someros, y aunque casi siempre aparece un hipertexto que se puede activar para obtener mayor información, no hay ningún enlace desde ahí con otros catálogos más científicos y exhaustivos. Por otra parte, hay errores de datación y de adscripción estilística en esas explicaciones turísticas, que ya he señalado en alguna otra ocasión: por ejemplo, el monumento a Goya erigido en 1960 ante la Lonja viene datado en 1908 (fig. 6).

(http://www.zaragoza.es/ciudad/postales/otros.htm consultado el 27/02/2012).

Ningún trabajo está exento de erratas de este tipo; pero precisamente una de las grandes ventajas de publicar un catálogo on line, es que los errores son fácilmente subsanables conforme se van detectando. Basta para ello asegurarse de que durante unos años va a haber un seguimiento de la

11 Empieza bajo el rótulo genérico de "Fotografías" que contiene fotos de diversa autoría agrupadas en varios epígrafes, entre los que figura uno titulado "Históricas" que merecería ser destacado en rótulo aparte, pues allí uno puede consultar 3884 fotos antiguas recogidas en el Archivo Municipal. Lo lógico quizá sería haberlas colocado junto a los epígrafes dedicados a los carteles de las fiestas y a los edificios de interés histórico-artístico, que en cambio figuran luego bajo el inexpresivo rótulo "de Interés", intercalado tras los que dan accesos a una cámara web instalada en la Plaza del Pilar, a una foto aérea de la ciudad bastante desfasada, y a tomas panorámicas de $360^{\circ}$ relativas a catorce monumentos principales confusamente denominadas como "visitas virtuales". Casi todas estas informaciones provienen del sitio web oficial de Zaragoza Turismo, al que también se puede acceder mediante un enlace desde el portal principal del Ayuntamiento, y allí si que tiene sentido el rótulo "Sitios de Interés", en el cual también puede encontrarse otra "Galería de Fotos" de la ciudad, incluidas algunas de monumentos artísticos en el espacio público. Es obvio que en todos estos casos el destinatario de estas informaciones e imágenes pintorescas es el gran público, y a veces incluso se estimula al pueblo llano para que responda con su aportación activa, como por ejemplo se hizo en el verano de 2006 a través del "Rally Fotográfico por el Casco Histórico". 
información que se cuelga en la web por parte de los responsables que la han redactado. Esto es lo que nos hemos comprometido a hacer los miembros del equipo de investigación "Observatorio Aragonés de Arte en la Esfera Pública" de la Universidad de Zaragoza, que en 2007 firmamos con el Ayuntamiento de Zaragoza un convenio por cuatro años, ya renovado en 2011, para la elaboración y seguimiento de este catálogo on line, que está colgado en la sección "Cultura" de la web municipal desde mediados de mayo de 2008 (http:/www.zaragoza.es/artepublico) (Fig. 7). Desde el principio, como en el caso barcelonés, dicha iniciativa se ha caracterizado por su aperturismo, pues las fichas no sólo han sido realizadas por los componentes del pequeño equipo de investigadores beneficiario inicialmente de sendos proyectos de investigación del Ministerio de Educación ${ }^{12}$ y del Gobierno de Aragón ${ }^{13}$ que lo han puesto en marcha, sino también por un cada vez más amplio elenco de colaboradores tanto en la propia Universidad de Zaragoza y en el Ayuntamiento de Zaragoza, como entre los miembros de la Asociación Aragonesa de Críticos de Arte, la Real Academia de Bellas Artes de San Luis, u otras instituciones. Por otro lado, lo mismo que en Barcelona, nuestro deseo es que este aperturismo a la colaboración de la sociedad no se limite únicamente a la redacción de las fichas e itinerarios para que el usuario los lea, sino que pueda participar cualquier ciudadano con sus observaciones y sugerencias. Por eso, hemos incluido en el margen izquierdo de nuestra página web un rótulo titulado "Ayúdanos a mejorar", que ya ha sido utilizado para hacernos llegar algunas interesantes consideraciones por parte de algunos usuarios (fig. 8). Otras opciones que se ofrecen, de abajo a arriba, en ese mismo lugar son la rúbrica "créditos" — con los nombres de todos los autores de las fichas-, el "mapa" de Zaragoza a partir del cual se puede acceder al catálogo de las obras, o entrar en "publicaciones" e "itinerarios" para seguir una ordenación prevista por especialistas, o bien se puede entrar directamente al "Catálogo" — para buscar por título, autor, emplazamiento,

\footnotetext{
12 El proyecto de investigación de tres años "Arte público para todos: su musealización virtual y difusión social", financiado por el Ministerio de Educación y Ciencia (código HUM200612803-C02-02) estuvo vigente desde diciembre 2006 a diciembre 2009.

${ }^{13} \mathrm{El}$ proyecto interdisciplinar de investigación "Un museo virtual de arte público de la ciudad de Zaragoza" financiado por la Consejería de Ciencia, Universidad y Tecnología del Gobierno de Aragón (código PM035/2006), estuvo en vigencia por dos años a partir del 1 de octubre de 2006.
} 
barrio, época, iconografía, materiales, o temática一 - todo ello precedido de una breve "Presentación".

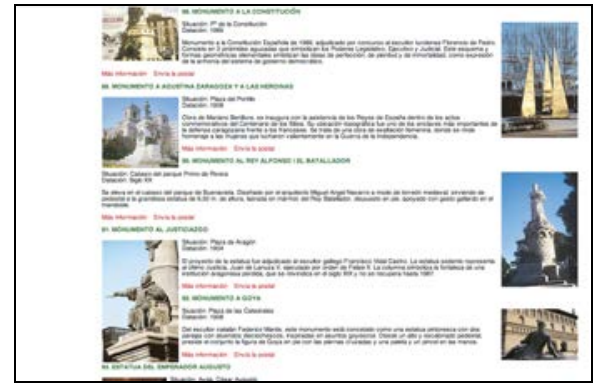

Fig. 6: Postales de monumentos zaragozanos en la web municipal.

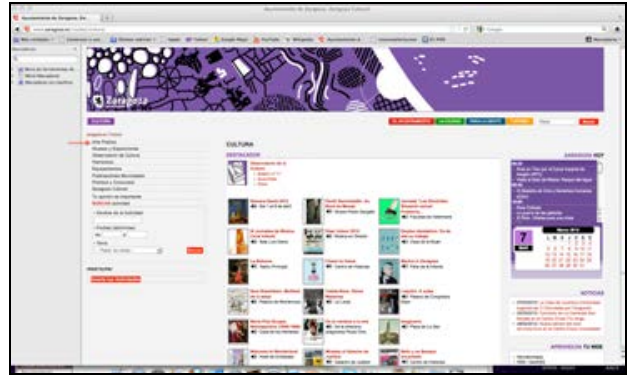

Fig. 7: Acceso al catálogo on line de arte público en la web municipal.

Por cierto, lo que de forma sintética se indica en esa presentación es cual ha sido el concepto de "arte público" que nos hemos planteado como punto de partida y de qué manera pensamos seguir avanzando en este trabajo, cuestión que nos ha planteado arduas diatribas. Por motivos prácticos, que no conceptuales, nos hemos centrado en obras que tengan vocación de perennidad - aunque en el espacio público nada es para siempre, todo resulta transitorio debido a la acción de los agentes atmosféricos, al vandalismo, o los cambios en el gusto, la política, etc.-, así que no hemos catalogado graffitis, performances, ni lo que los franceses llaman poéticamente arts de la rue, a pesar de que estas manifestaciones artísticas nos merecen gran consideración, como quedó de manifiesto en el que seminario internacional sobre arte en el espacio público que recientemente organizamos entre el Ayuntamiento y la Universidad de Zaragoza ${ }^{14}$, donde fue presentado al público por primera vez de forma operativa nuestro catálogo on line el día 24 de mayo de 2008. Nuestro objetivo es catalogar todo monumento artístico o conmemorativo que de forma permanente esté instalado en el espacio

\footnotetext{
${ }^{14}$ La Sociedad Municipal "Zaragoza Cultural” y nuestro equipo de investigación organizaron un seminario internacional titulado Arte en el espacio público: barrios artísticos y revitalización urbana, que se celebró los días 23 y 24 de mayo de 2008 en el Centro de Historia de Zaragoza, cuyas actas se publicaron en 2009 en un libro coordinado por Blanca Fernández Quesada y Jesús Pedro Lorente, dentro de la serie editorial "Modos de Ver" de Prensas Universitarias de Zaragoza.
} 
público o sea visible desde él. Como hicieron nuestros colegas de Barcelona con motivo del Forum 2004, nosotros comenzamos en vísperas de la Expo 2008 haciendo accesible al público el catálogo de esculturas, monumentos, $\mathrm{u}$ otras piezas tridimensionales, pero al año siguiente también estaban incluidos los relieves, pinturas murales $\mathrm{u}$ otros elementos adosados a muros visibles por cualquier paseante desde la calle. Con el tiempo, nos gustaría abarcar todo el arte público con vocación de perennidad en sus más variadas manifestaciones, incluyendo fuentes - por ahora sólo hemos catalogado las que tienen algún componente arquitectónico-escultórico-, jardines de diseño, o símbolos conmemorativos, lo mismo que en la web del Ayuntamiento de Barcelona, donde ya están en este momento catalogando placas, árboles de la memoria u otros elementos de lo más variopinto.

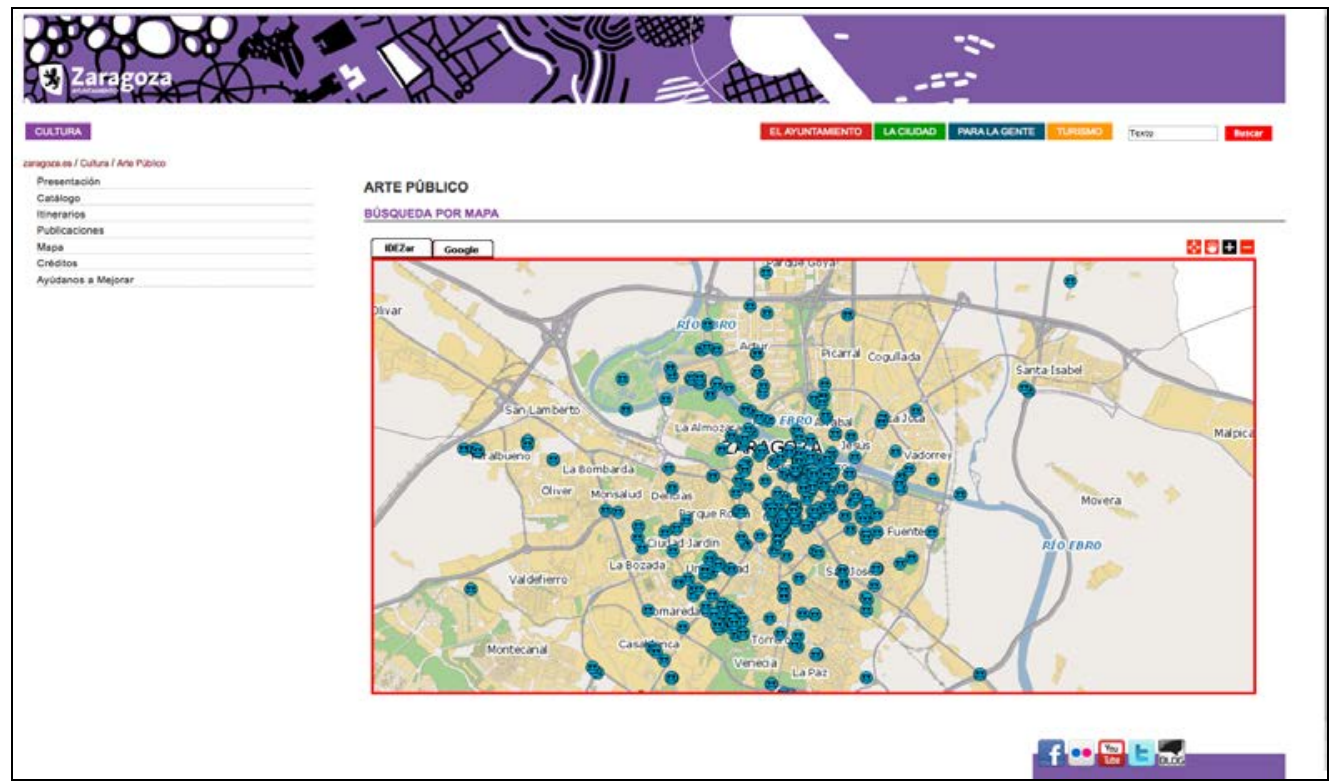

Fig. 8: Mapa de localización y acceso a las fichas en el catálogo de arte público en la web municipal (http://www.zaragoza.es/artepublico)

La idea a largo plazo es unificar los sistemas de consulta y poder cruzar datos informáticamente entre los proyectos similares que se están realizando en otras ciudades españolas y europeas, de manera que el modelo de ficha catalográfica que hemos adoptado consta necesariamente de los mismos 
campos que la del antecedente barcelonés: título, emplazamiento, autores, dimensiones, fecha, promotor/donante/medio de adquisición, propietario, inscripciones, breve biografía del artista, breve biografía del representado (si ha lugar), crónica histórica, y comentario final. Este comentario en Barcelona era una valoración o explicación personal que se encargó normalmente a historiadores del arte, pero también a gentes de letras u otras personalidades públicas; por lo que, con objeto de unificar en parte la información a lo largo de todas las fichas del catálogo, se encomendó previamente a los periodistas Jaume Fabre y Josep Maria Huertas, la redacción de la crónica histórica de cada pieza, a partir de los datos que el Ayuntamiento les proporcionó y los que ellos buscaron en otras fuentes secundarias. Nosotros, en cambio, hemos tenido que encargar por completo todos los campos de que consta cada ficha catalográfica al experto o expertos que la firman (fig. 9).

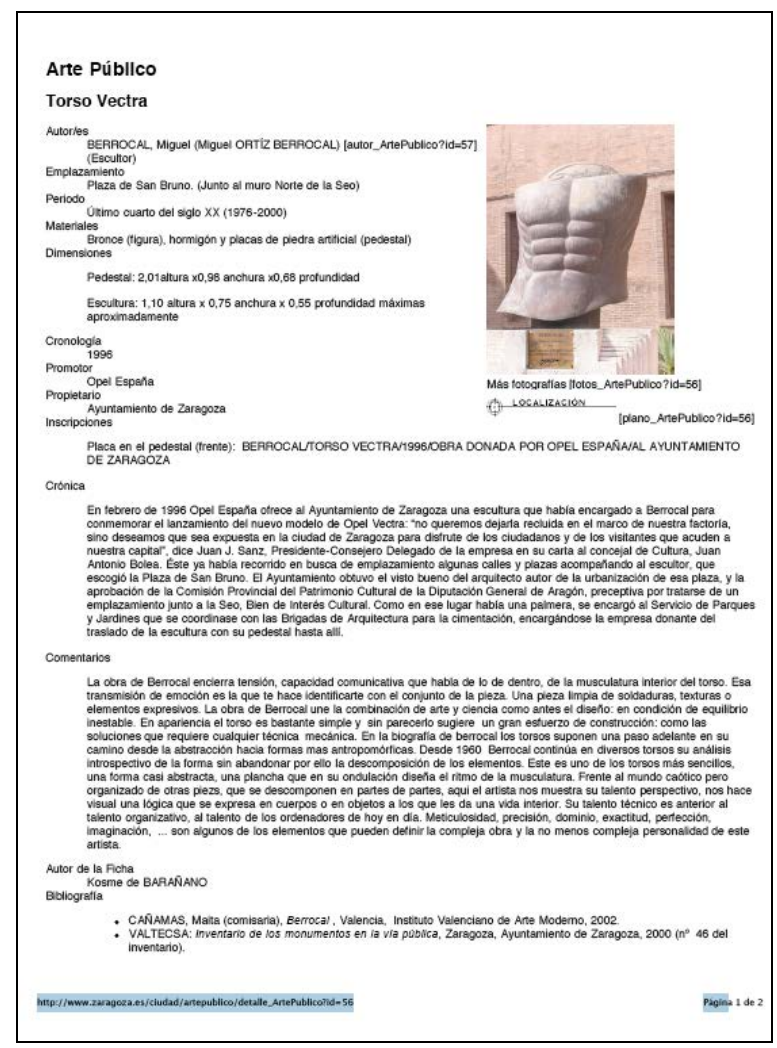

Fig. 9: Ficha de la escultura Torso Vectra de Miguel Ortiz Berrocal (versión PDF para impresión) 
A diferencia del catálogo barcelonés, el nuestro aún no cuenta con fichas de monumentos desaparecidos, pero debido a que tenemos en nuestro equipo expertos en "arqueología industrial", desde el principio hemos incluido los numerosos elementos patrimoniales de este tipo presentes perennemente en el espacio público zaragozano, tanto si se trata de una antigua embarcación junto al canal, de una vieja locomotora colocada en la mediana de un puente, de una rueda de molino en una rotonda, o de la chimenea de una antigua industria — pues si el resto del edificio ha desaparecido, poco queda ya de su naturaleza arquitectónica y se ha convertido en una especie de monumento conmemorativo o estético - (fig. 10). Del mismo modo, teniendo en el equipo prestigiosos arqueólogos, no podemos dejar de catalogar vestigios históricos que se muestran en nuestro espacio público, perdida ya otra función que no sea la puramente monumental y ornamental. Por otro lado, mientras que en el catálogo on line del Ayuntamiento de Barcelona no se incluyen fachadas de monumentos religiosos — salvo los de titularidad municipal-, ni apenas hay ejemplos de edificios de otros poderes públicos o de casas particulares, en la web zaragozana sí estamos estudiando decoraciones artísticas dignas de ser destacadas en los recintos o las fachadas de edificios de todo tipo: iglesias, palacios cívicos, bancos o cajas de ahorro, viviendas particulares, etc.

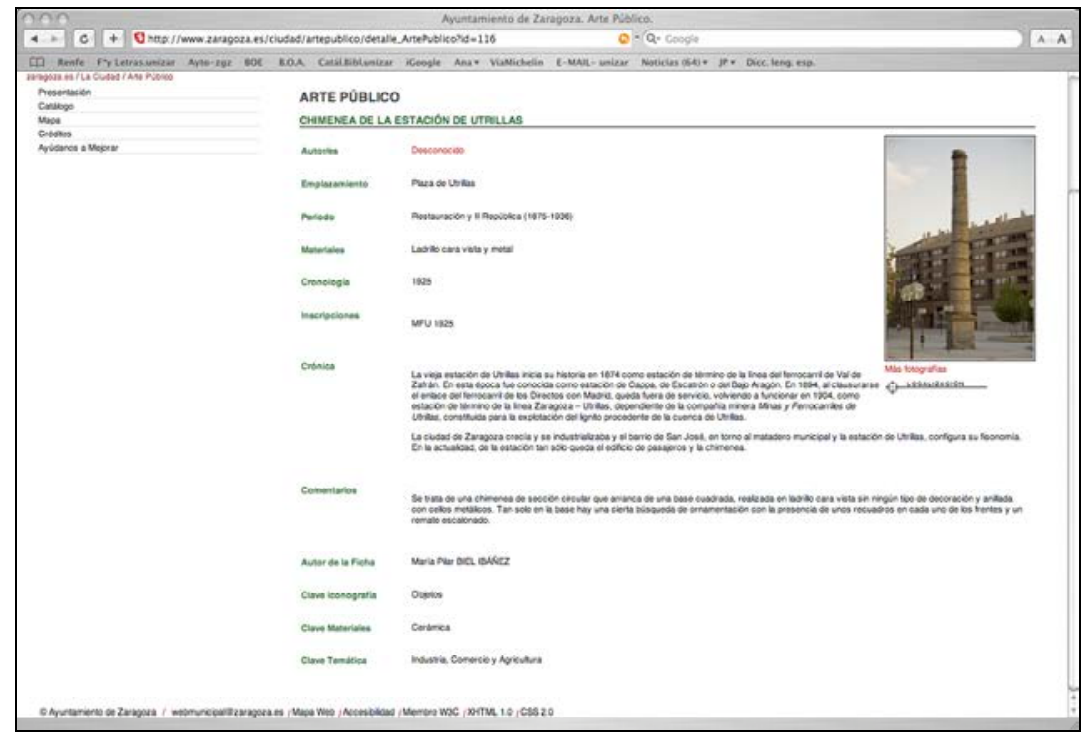

Fig. 10: Ficha de la Chimenea de la Estación de Utrillas (captura de pantalla) 
Otro aspecto en el que la definición de "arte público" nos ha planteado dudas se refiere a piezas que no se encuentran en la calle, sino en recintos cerrados. ¿Podemos seguir considerando arte público aquel que se halla tras cercas o verjas que sólo permiten el paso al viandante en determinados horarios y condiciones? En general, nosotros hemos tendido a considerar que sí, porque de lo contrario no podríamos incluir algunas piezas artísticas de la Expo, ni tampoco las esculturas de Pedro Tramullas $u$ otros artistas que se encuentran en el patio del Edificio Pignatelli — sede principal de la Diputación General de Aragón-, o las que adornan los patios del antiguo matadero - actualmente sede del C.C. "Salvador Allende", entre otros usos cívicos-, o las que hay al aire libre en el campus de la Universidad, o en los recintos ajardinados de otras instituciones públicas accesibles a cualquiera. Pero, mientras que la web de escultura urbana del CPIP "Cesáreo Alierta" está actualmente catalogando las esculturas instaladas en los patios de residencias o de los colegios de enseñanza infantil y primaria e institutos de enseñanza media, en el portal del Ayuntamiento de Zaragoza no los hemos incluido, pues por la seguridad de los menores se supone que el público en general no tiene permitido el acceso a los colegios, tanto si son públicos como si son privados, salvo en ocasiones excepcionales o solicitando un permiso.

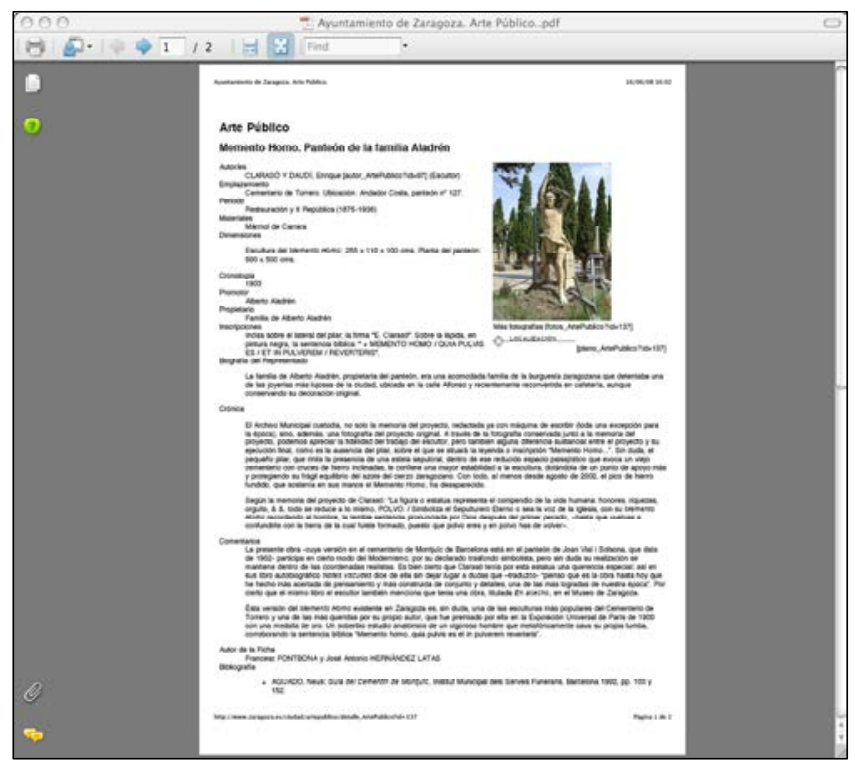

Fig. 11: Ficha de la escultura Memento Homo de Enrique Clarasó (versión PDF para impresión). 
Por otra parte, nuestros colegas de Barcelona han excluido totalmente las obras de arte fúnebre en el recinto de los cementerios, que en el caso zaragozano sí hemos incluido (fig. 11), aunque no de forma exhaustiva sino sólo a través de una selección antológica de algunas de las mejores piezas con tal de que sean obras únicas, no producciones en serie de la industria funeraria, y de que no estén en el interior de alguna capilla, panteón, u otro espacio arquitectónico - pues al fin y al cabo el camposanto zaragozano es todavía un espacio público al aire libre sin control de acceso, que simplemente tiene algunas restricciones horarias de ingreso comparables a las de ciertos parques y otros recintos urbanos controlados, para evitar vandalismos nocturnos.

Más complicada es la cuestión en el caso de obras que se hallan en el interior de edificios. La bibliografía internacional sobre arte público —especialmente los textos en inglés - suele igualmente considerar como tal aquel que los ciudadanos se encuentran en edificios de tránsito como aeropuertos, estaciones de tren o metro, galerías y centros comerciales, $u$ otros espacios cubiertos donde la gente pueda deambular libremente. En la web del Ayuntamiento de Barcelona no los consideraron inicialmente; pero ahora ya han comenzado a incluir en su catálogo on line muchas decoraciones artísticas de las estaciones del metro, trenes de cercanías, etc. No es de extrañar, pues ya incluyeron desde el principio esculturas conservadas en edificios municipales, en especial las que cualquier ciudadano que vaya a la Casa de la Ciutat encuentra en el gran vestíbulo de la misma nada más entrar por la Plaza de Sant Jaume. También nuestra Casa Consistorial en la Plaza del Pilar cuenta con una importante colección artística a la vista de cualquiera que realice gestiones burocráticas en el gran vestíbulo de la planta baja, en el atrio, en las escaleras de honor y en los pasillos del piso principal; pero nuestro criterio no es por ahora incluirlas, pues de hacerlo no habría razón para dejar de incluir las piezas expuestas en los museos municipales o de otra titularidad, la mayor parte de los cuales son de ingreso gratuito en Zaragoza. En todo caso, la intención es que el trabajo vaya ampliándose a lo largo de los años; pero ahora nuestra ambición no solamente es aumentar el número de fichas, sino más bien complementarlas —como nuestros colegas de Barcelona- con nuevos itinerarios, con visitas guiadas e información a 
distintos niveles, como si los usuarios estuvieran visitando un verdadero museo... y a todos los efectos debería ser considerado así, aunque sea un "museo virtual".

\section{BIBLIOGRAFÍA CITADA}

AZCUE, Leticia (introd.) (2007): $1^{\text {er }}$ Encuentro Internacional Tecnologías para una museografía avanzada, Madrid, ICOM-España (Madrid, 21-23 nov. 2005).

BELlido GANT, Ma Luisa (2001): Arte, museos y nuevas tecnologías, Gijón, Trea, 2001 (esp. el capítulo VIII: “Museos virtuales y digitales”, págs. 237-259).

BEARMAN, David \& Jennifer TRANT (eds.) (2001):.Museums and the Web 2001: selected papers from an international conference.- Pittsburg, PA : Archives and Museum Informatics, cop. 2001.

CARRERAs MONFORT, Cèsar y Glòria Munilla CABrillana (2005): Patrimonio digital,Barcelona, UOC.

CARRILlO, Jesús (2004): Arte en la red, Madrid, Cátedra.

Cirlot Valenzuela, L., Buxó Rey, Ma . J., CASAnOvas Bohigas, A., EstéveZ De La Escalera, T. (eds.): Arte, Arquitectura y Sociedad Digital, Barcelona, Universitat de Barcelona, 2007.

DELOCHE, Bernard (2002): El museo virtual, Gijón, Trea (ed. orig. francés, 2001)

LORENTE, Jesús Pedro (2008): “El arte público en las páginas web de los ayuntamientos españoles", en CABAÑAS, M., LÓPEZ-YARTO, A., RINCÓN, W. (eds.): Arte, poder y sociedad en la España de los siglos XV a XX, Madrid, CSIC, págs. 699-710.

LORENTE, J. Pedro (2008): "Hacia un museo virtual de arte público en Aragón", en LOMBA, Concha y Cristina GIMÉNEZ (coords.): El arte del siglo XX. Actas del XII Coloquio de Arte Aragonés). Zaragoza, IFC-DGA, 2009, p. 451-464.

MARCHÁN, Simón (comp.) (2005): Real/virtual en la estética y la teoría de las artes, Barcelona-Buenos Aires-México, Paidós.

MCTAVISH, Lianne (2006): "Visiting the virtual museum: art and experience online" en MARstine, J. (ed.): New Museum Theory and Practice. An Introduction. Malden-Oxford, Blackwell Publishing, págs. 226-246.

Welger-BARBOZA, Corinne (2001): Du musée virtuel au musée médiathèque : le patrimoine à l'ère du document numérique. Paris : L'Harmattan. 